\title{
Marine diversity: the paradigms in patterns of species richness examined*
}

\author{
JOHN S. GRAY \\ Biological Institute, University of Oslo, Pb 1064 Blindern, 0316 Oslo, Norway.
}

\begin{abstract}
SUMMARY: The two central paradigms of marine diversity are that there is a latitudinal cline of increasing species richness from poles to tropics and that species richness increases with depth to a maximum around 2,000 $\mathrm{m}$ and thereafter decreases. However, these paradigms were based on data collected in the late 1950's and early 1960's. Here I show that the 1960's data, are not representative and thus the paradigms need re-examination. New data from coastal areas in the northern hemisphere record species richness as high as the highest recorded in the deep-sea. Whilst this suggests that the cline of increasing diversity from shallow to deep-sea does not exist, however, the database for the deep sea is not sufficient to draw such a conclusion. The basic problem with the data from the 1960s is that samples were taken on ecological scales and yet they are used to answer evolutionary questions. The questions that such data were to answer were why do the tropics have higher species richness than polar regions or why do deep-sea sediments have more species than coastal sediments? Evolutionary questions need data from much larger spatial areas. Recently, data representative of large scales have been collected from coastal areas in the northern hemisphere and show that there is a cline of increasing species richness from the Arctic to the tropics, but there does not yet seem to be a similar cline in the southern hemisphere. A number of hypotheses have been proposed for the observed patterns in biodiversity. In terrestrial ecology the energy-productivity hypothesis has gained wide acceptance as an explanation for the latitudinal gradient. Here I examine this and other hypotheses critically. Finally an analysis of research priorities is made. Assessment is urgently needed of the spatial scales and dynamics of species richness from point samples to assemblages, habitats and landscapes, especially in coastal areas and in the tropics, where the threats to biodiversity are greatest. New technologies are available, such as side-scan sonar, acoustics, and under-water digital video cameras but as yet have been relatively little used. Conservation of marine biodiversity must be based on sound theory, yet marine diversity studies lag well behind those of terrestrial habitats.
\end{abstract}

Key words: shallow-deep, latitude, longitude, hypotheses, conservation.

\section{INTRODUCTION}

In 1968 Howard Sanders (1968) produced a remarkable paper that stimulated a debate on marine diversity that has continued for 30 years. His basic hypotheses were that marine diversity a) followed the terrestrial pattern showing an increasing cline from the poles to the tropics and that b) contrary to

\footnotetext{
*Received April 19, 2001. Accepted May 18, 2001.
}

general belief diversity increased with depth from shallow coastal areas to $2000 \mathrm{~m}$, the limit of his study. Thorson, (1957) had earlier showed that species numbers of nudibranchs and amphipods increased in numbers from the Arctic to the Boreal and to the tropics. Likewise Stehli et al. (1967, 1969) had shown similar trends for species numbers of bivalves. Thus the latitudinal gradient of increasing species richness from Arctic to tropics had been established. 
Sanders, however, did not simply count numbers of species, but collected samples from marine soft sediments with a semi-quantitative anchor-dredge. He followed Whittaker (1960) in arguing that one could only compare diversity within similar habitats and that the soft sediments he studied was a withinhabitat comparison. Sanders not only described the patterns, but also proposed mechanisms as to how the patterns had arisen. His stability-time hypothesis states that in environmentally variable shallow and/or polar areas adaptation by individuals is primarily to the physical environment rather than to other species. In contrast in the deep sea and tropical areas the environment is fairly constant and adaptation is by means of competition to other species. Thus the species richness of shallow and polar areas is "physically controlled", whereas that of the deep sea and tropical areas is "biologically accommodated", Sanders (1968). This idea was hotly debated and alternative explanations based on disturbance/predation (Dayton and Hessler, 1972), and on species-area relationships, (Abele and Walters, 1978) were proposed.

The ideas that, just as on land, there is a trend of increasing diversity from poles to tropics and that coastal diversity is low compared with that of the deep-sea are firmly accepted in modern text-books, (e.g. Gage and Tyler, 1992; Huston 1994; Levinton 1995; Begon et al. 1995). The, low coast-high deep sea diversity idea, was strengthened further by results of Grassle and Maciolek (1992) who analysed samples of deep-sea sediments from depths between 1,500 and 2,100 m off the east coast of North America and report a total of 798 species from $21 \mathrm{~m}^{2}$ of sediment. These results were claimed to "indicate a much greater diversity of species in the deep sea than previously thought" and "in contrast to the deep sea, shallow water marine communities outside of tropical areas have relatively few species", Grassle (1989, 1991). However, Gray (1994), Coleman et al. (1997) and Gray et al. (1997) showed high species richness in soft sediments in coastal areas and thus questioned whether there is a cline of increasing species diversity from shallow to deep sea.

Not all areas of the coast or the deep sea have high species richness. Coastal areas with high physical variability, such as estuaries and exposed sandy beaches, (Brown and Maclachlan, 1990) have low diversity. Similarly Jumars (1976) showed low species numbers in the deep sea Santa Catalina basin, off the coast of California and low diversity occurs in the Norwegian Sea at depths of 4,000 m, (Rex et al., 1993). Thus it is likely that there is a considerable variability in species: area relationships in both coastal and deep-sea areas.

In this paper I will critically examine the patterns of marine diversity, identify problems and then suggest ways forward for research. Diversity, of course, is more than simply the number of species, (see Gray, 2000). Yet here I confine myself to one aspect only species richness.

\section{THE PARADIGMS IN PATTERNS OF MARINE SPECIES RICHNESS}

Levinton (1995), summarizes what have become paradigms of gradients of diversity, (species richness) as "The best-known diversity gradient is an increase of species diversity from high to low latitudes in continental shelf benthos, in the plankton in continental shelf regions and in the open ocean"; and "... there is a regular change in benthic diversity from coast to abyssal plain, (see also Briggs, 1991, 1994). Species diversity of macroinvertebrates and fishes increases with depth, to a maximum just seaward of the continental rise, and then decreases with increasing distance towards the abyssal plain". These two paradigms represent evolutionary rather than ecological scale processes and ecological scale data sets are inappropriate to answer evolutionary questions, unless the samples are truly representative of evolutionary patterns.

Table 1 shows scales of diversity (here species richness) based on Whittaker but modified by Gray (2000). A single sample within a habitat is called point diversity. (Note that replicate grabs summed together constitute a sample). A number of samples within a habitat measures $\alpha$ species richness, over a large area samples measure $\gamma$ diversity and at an even larger scale, that of the region or biogeographical province, $\varepsilon$ diversity. Note that there is no $\beta$ diversity as this is a different concept and relates to changes in the identity of species along an environ-

TABLE 1. - Scales of Species richness based on Whittaker (1985) and modified by Gray (2000).

$\begin{array}{ll}\text { Point diversity } & \text { of a single sample } \\ \alpha \text { diversity } & \text { of samples within a habitat } \\ \gamma \text { diversity } & \text { of a larger unit (e.g. a landscape or island) } \\ \varepsilon \text { diversity } & \text { the total species richness of a group of large } \\ & \text { areas (a region or biogeographical province) }\end{array}$


mental gradient (See Gray, 2000 for a fuller explanation and also Loreau, 2000).

\section{The latitudinal gradient of species richness}

In comparing patterns of species richness the local (ecological-scale) samples should be representative of province-size (evolutionary) scales. Rosenzweig, (1995) defines a biological province as "a self-contained region whose species originate entirely by speciation within the region". This is unlikely to be an appropriate definition for marine provinces since marine systems are more "open" and immigration of species will be common. Briggs (1995) however, described marine biogeographical provinces and this suggestion has recently been modified by Watling (unpubl. but see http://marine.rutgers.edu/ OBIS/biogeo/watling.htm). Roy et al.'s (1998) study of prosobranch species richness shows clear boundaries between biogeographical provinces on the Atlantic and Pacific coasts of USA. Stuart and Rex (1994) argue that for prosobranch gastropods local diversity is positively and significantly related to regional (i.e. biogeographical province) diversity. Cornell and Karlson (1999) found similar results for corals. Whether or not this is generally true remains to be confirmed. Cornell and Lawton (1992) in a theoretical analysis of local and regional scale processes affecting species richness argue that the principal direction of control is from regional to local. Thus biogeographic rather than local scale processes are the key to understanding species richness patterns. Yet most marine studies have concentrated almost exclusively on local scale processes.

Thorson (1957) recorded an apparent increase in species diversity of some taxa of hard substratum epifauna from the Arctic to the tropics (Thorson, 1957). Later Stehli et al. (1967) showed that bivalve molluscs, at species, genus and family levels increased in diversity towards the tropics in the Indo-Pacific. Thorson's data show an average of 9 species of nudibranch in Arctic areas 22 in the boreal and 128 in the tropics and for Amphipoda 150 species in the Arctic 180 species in the Boreal and 195 in the tropics. Stehli's data for bivalves shows ca 50 species at $70^{\circ} \mathrm{N}$, ca 130 at $50^{\circ} \mathrm{N}$, ca 500 in the tropics, ca 200 species at $30^{\circ} \mathrm{S}$ and ca 70 species at $60^{\circ} \mathrm{S}$. These are extremely small numbers of species on which to make general comparisons and clearly do not represent evolutionary-scale patterns.

Sanders (1968) synthesis was based on data collected along a transect, from Gayhead, USA to
Bermuda, (Hessler and Sanders, 1967) and then from a variety of different geographical areas, from the boreal to the tropics and from estuaries to the deepsea slope, (Sanders, 1968). The samples were taken with an anchor dredge, which is a semi-quantitative sampler only and designed to catch many species. Sanders used not the total species richness, but the polychaete-bivalve fraction of the fauna. He claimed that this represented usually over $80 \%$ of the total number of species. Abele and Walters (1978) reanalysed the data and showed that the polychaetebivalve fraction varied from an average of $38 \%$ in estuaries, to $60 \%$ on the shelf, around $70 \%$ in the deep sea, to over $80 \%$ in shallow waters. They argued that the data, therefore, were unlikely to be representative of total species richness. Thus Sanders data relate to whether or not there are gradients in species-richness of polychaetes and bivalves from poles to tropics and shallow to deep-sea. Two questions arise, firstly, are the number of species of polychaetes and bivalves in Sanders analyses representative of the two gradients? And secondly are the methods of comparison used appropriate?

The maximal number of species in Sanders comparison was less than 100. Can one base an analysis of evolutionary-scale patterns on such a small number of species? In the Osloford a single $0.1 \mathrm{~m}^{2}$ grab sample will contain up to 50 species of macrofauna retained on a $1 \mathrm{~mm}$ mesh sieve. In Port Phillip Bay, Australia, 197 species were recorded from a single set of five simultaneously taken samples from one sandy station, an area of $0.5 \mathrm{~m}^{2}$ (Poore et al., 1975). In the Bass Strait one $0.1 \mathrm{~m}^{2}$ sample comprised 187 species and 12 out of 38 taken on one occasion comprised more than 100 species (Coleman, 1997). Thus, techniques have improved greatly since the 1960's and today we have good quantitative data rather than the semi-quantitative data available at that time. Since the 1960s there has been extensive environmental monitoring in coastal areas and thus we have a far more detailed knowledge of the occurrence of species today. What is clear is that the species numbers used in comparative studies in the late 1950's and early 1960's are almost certainly not representative of regional scale (evolutionary) processes and cannot be used for comparative purposes.

Sanders (1968) not only provided data and hypotheses for patterns of species richness but also developed a method for comparing samples of different sizes. Sanders' rarefaction technique overestimated species number, but Hurlbert (1971) devel- 
oped the method in order to correct this problem. The rarefaction method is based on the distribution of individuals among species for the total sample. Using an algorithm that assumes a common evenness (dominance) pattern and a random distribution of individuals among species it produces $\mathrm{E}\left(\mathrm{S}_{\mathrm{n}}\right)$, the expected number of species (s) in a sample size of (n) individuals. Fager (1972) and Gage and May (1992) showed that there were problems with these assumptions and that estimates of the number of species was highly dependent on the evenness. Gray (1996) analysed field data and showed that low evenness (high dominance) occurs at small sample sizes and high evenness (low dominance) at large sample sizes. He showed that rarefaction greatly overestimates the true number of species and especially in small samples, the degree of overestimation being proportional to evenness. May (1993) states that $\mathrm{E}\left(\mathrm{S}_{\mathrm{n}}\right)$ does not measure species richness but evenness and points out "it is possible for two communities to have very different values of $E\left(S_{n}\right)$ and the same total number of species". Yet the rarefaction is still widely used to compare diversity, (e.g. see Lambshead's review, 1993).

As an example, Rex et al. (1993) compared deep sea macrofauna from the North and South Atlantic using rarefacted data and showed a significant cline of increasing diversity moving from poles to tropics for isopods, bivalves and gastropods, although the cline in the southern hemisphere was less clear. Table 2 shows the data on which the analyses were based.

Again the numbers used in the comparative analyses are extremely small, even though the total number of individuals was 214,508 . (No estimate of the total number of species was given). In fact it is quite common to use $\mathrm{E}\left(\mathrm{S}_{50}\right)$ to compare changes in diversity (Rex, 1983). To take a practical example if one were to take a random sample of 50 (or even 250 individuals) from pooled grab samples containing tens of thousands of individuals, would you expect this to provide a good estimate of the total species

TABLE 2. - Data on which the latitudinal gradient of deep-sea benthos is based, (Rex et al. 1993). $\mathrm{E}(\mathrm{S})=$ the estimated number of species (s) for a sample size of (n) individuals using the rarefaction procedure of Hurlbert (1971).

\begin{tabular}{lcc}
\hline Taxon & Maximal $\mathrm{E}\left(\mathrm{S}_{\mathrm{n}}\right)$ & $\mathrm{n}$ \\
\hline Isopoda & 56 & 200 \\
Bivalvia & 17 & 75 \\
Gastropoda & 23 & 50 \\
\hline
\end{tabular}

richness of the area? The answer must be no, yet this is what is done routinely by using the rarefaction technique.

For example, Kendall and Aschan (1993) have made a comparison of the sediment-living macrofauna at a site at $123 \mathrm{~m}$ depth at $78^{\circ} \mathrm{N}$ off Svalbard, Norway, with a site off Northumberland, $50^{\circ} \mathrm{N}$ UK at $80 \mathrm{~m}$, with that at $30 \mathrm{~m}$ off the coast of Java, $7^{\circ} \mathrm{N}$. Using $\mathrm{E}\left(\mathrm{S}_{200}\right)$ they obtained $32.9 \pm 1.4,34.6$, and $33.2 \pm 1.9$ where the \pm are $95 \%$ c.i.'s. They claimed that this data showed no trend in latitudinal species richness. Paterson (1993) also has used similar methods to compare deep-sea diversity and did not find the latitudinal cline found by Rex et al. (1993). However, Kendall and Aschan's data are from small sample sizes of very limited numbers of species, and in addition depth varied considerably. In coastal areas small differences in depth are known to alter species composition and probably species richness (Olsgard and Gray, 1996, Ellingsen 2001 in press). I do not believe one can make generalisations about latitudinal species richness from such small sample sizes and am not convinced that these studies represent evolutionary-scale faunal provinces, but are rather ecological data sets.

There are alternatives to rarefaction methods. Colwell and Coddington (1994) have produced a randomization programme that is available over the Internet, (Estimates, available at http:// viceroy.eeb.uconn.edu/EstimateS). This method takes a sample at random and records species number adds a second and calculates cumulative species number and so on. This process is repeated a hundred or more times so that curves of randomized species accumulation with c.i.'s are produced. We, (Gray et al., 1998) have used a similar method, which differs from Colwell's in that it calculates the cumulative number of species in all samples of size 2, 4, 6, 8 etc until the total sample size. The methods differ in that Colwell's is sampling without replacement whereas, Gray et al.'s method is with replacement. There is still the problem of setting the appropriate size at which to compare samples. The species-area curve should give a good estimate of the local species richness and comparisons should be at the largest possible size. Comparison of species richness, based on samples of a few hundred individuals, (or of a few square meters), are inappropriate, even for local comparisons let alone over province scales.

There are however, recent data sets that do represent provincial (evolutionary) scales. Species 
records of prosobranch molluscs taken from along the coasts of N. America, (1,907 species in the eastern Pacific and 2,009 in the western Atlantic), showed clear gradients of increased species richness from the North Pole to the tropics, (Roy et al., 1996, 1998). Although there are likely to be differences in sampling effort over these latitudinal gradients there is little doubt that the large differences in species richness found are real. Roy et al. show convincingly that the gradient correlates with mean sea-surface temperature and suggest that species richness is probably related to some measure of productivity.

A recent compilation of all known species along the Norwegian coasts by Brattegard and Holthe, (1997) gives a total of around 4,500 species of macrofauna and macroalgae. The data for $70^{\circ} \mathrm{N}$ show 90 species of Nudibranch, 246 species of gammarid amphipods alone and 117 species of bivalves. Thus the old data of Thorson and Stehli (still repeated in textbooks) are out of date and far from representative. An analysis of the new Norwegian data does however, show clearly that there is a cline of decreasing diversity from $60^{\circ}$ to $70^{\circ} \mathrm{N}$, (Olsgard, in prep.). Similarly Boucher and Lambshead (1995) analysed data on nematodes from temperate estuaries and sublittoral, tropical sublittoral, bathyal, abyssal and trench and found that tropical species richness was lower than temperate and there was an inverse relationship between productivity and species richness.

What is surprising about Roy et al.'s (1998) paper, is that although the studies were done only in the northern hemisphere conclusions on global scales are made. Roy et al. (1998) state that "latitudinal gradients, peaking in the tropics and tailing off toward the poles" are the rule, yet they did not take any samples in the southern hemisphere!

Rex et al.'s (1993) deep sea data show a cline of increasing species richness from the Norwegian Sea to the tropics, but show a much less clear trend in species richness in the southern hemisphere. There is a huge spread in the number of species at each latitude save for the tropics where the two samples had similar, high $\mathrm{E}\left(\mathrm{S}_{\mathrm{n}}\right)$ values. Had the variance been similar in the tropics it is unlikely that there would be significant trends. Data from isopods from the Pacific and Atlantic oceans, (calculated in a similar manner to that of Rex et al., 1993), do not show an increasing cline of species richness towards the tropics (Poore and Wilson, 1993).

Crame (2000) has made a comprehensive study of living marine Bivalvia (Mollusca) based on 29 regional faunas. The data show strong latitudinal gradients in taxonomic diversity, with a strong asymmetry between the Northern and Southern Hemisphere. The gradient in the Northern hemisphere is more regular than the Southern. Northern gradients are also characterized by a marked inflection at approximately 30 degrees $\mathrm{N}$ as also shown in gastropods by Roy et al. (1996, 1998). Crame's study also has a taxonomic and stratigraphic analysis that reveals the steepest latitudinal gradients are associated with the youngest bivalve clades. This provides further evidence that the Tropics have served as a major centre of evolutionary innovation. Even though some sort of retraction mechanism cannot be completely ruled out, these gradients are most likely the product of primary radiations.

Clarke (1992) in his review, shows that the Antarctic has high diversity for many taxa and questions that the latitudinal gradient holds for the southern hemisphere. Lowry (pers. comm.) analysed the fauna of islands from New Zealand to Antarctica and found no clear gradient of decreasing species richness, but recorded changes in the frequencies of various taxa. Furthermore, data from Australia (Coleman et al., 1978, 1997) and Gray et al. (1997) show extremely high species richness at $40^{\circ} \mathrm{S}$ and there are no tropical data yet published showing as high species richness, (see also Crame's 2000 data on bivalves showing a hot-spot in Australia). Clearly there is a need for more quantitative data from the southern hemisphere and from the tropics, but data available do not show a clear cline of increasing diversity from Antarctica to the tropics. This pattern may also occur in terrestrial systems since the Fynbos of S. Africa, (Cowling et al., 1992) and Kwongan of south-western Australia have extremely high plant species diversity (Hopper, 1992, Marchant, 1991). Thus one can summarise that in the marine domain there is a cline in increasing species richness from Arctic to tropics but no clear evidence yet that there is a similar cline in the southern hemisphere.

\section{The longitudinal gradient of species richness}

Coral reef diversity is highest in Indonesia (600 species) and decreases radially from there across the Pacific and Atlantic, (Veron, 1995). Data on angiosperms in Asia, Europe and N. America show the same pattern (Latham and Ricklefs, 1997). Crame's study of living and fossil bivalves (Crame, 2000) shows that highest species richness occurs in southern China-Indonesia-NE Australia region and 
TABLE 3. - Comparison of data on which the paradigm of low coastal to high deep-sea species richness is based

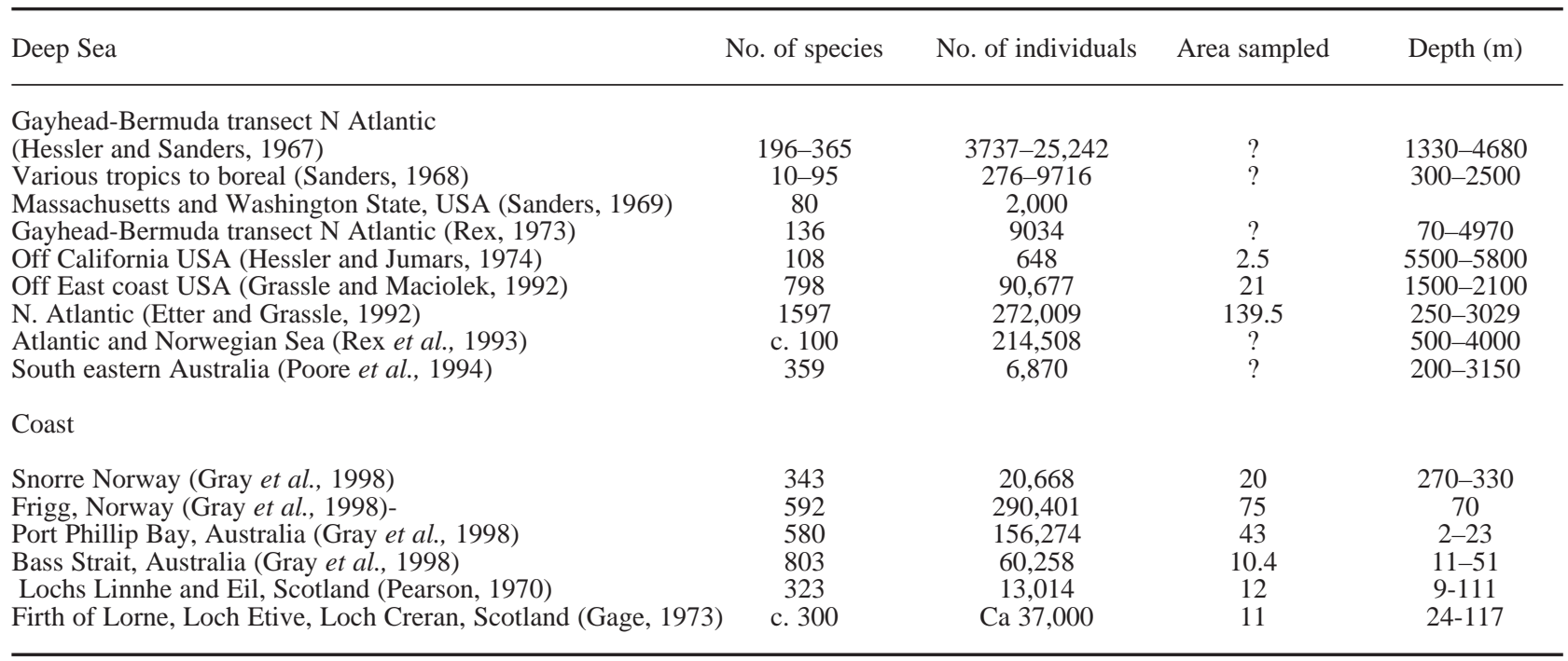

is closely associated with the world's richest development of coral reefs. These data suggest that the South East Asian area is a centre of marine faunal species richness and that species have radiated out from this area. Crame's study shows that the youngest clades occur in tropical areas with markedly lower diversity of some bivalve clades, such as the heteroconchs, in the high-latitude and polar regions. This, he suggests, may simply reflect the fact that they are not yet fully established there and it may take periods of tens or even hundreds of millions of years for bivalve clades to disseminate fully across the earth's surface.

\section{The shallow (coast) to deep sea gradient of species richness}

Table 3 shows the number of species and individuals, depth and area used to make generalisations about the shallow: deep-sea diversity gradient. It is clear that only recent data are of a quality that allows us to make generalisations. Table 3 shows that similar areas of seabed from coastal habitats of Norway and Australia are as rich in species as that of the only comparable deep-sea study (Grassle and Maciolek, 1992). Grassle and Maciolek reported 698 species from 90,000 individuals whereas the Bass Strait data, the most rich of our four, shows 803 species from 60,258 individuals and $10.2 \mathrm{~m}^{2}$. Other surveys support high number of species in coastal areas: e.g. 572 species from $12.3 \mathrm{~m}^{2}$ in Western Port, Australia (Coleman et al., 1978), and 620 species from $50 \mathrm{~m}^{2}$ and 40,000 individuals on the Norwe- gian shelf at 70-305 m depth (Gray, 1994). (The extremely high diversity shown for Bass Strait needs a comment. Here the sediment is of biological origin, calcareous shells of Mollusca and Foraminifera etc and is coarse. Shell-gravels are known to be rich in species but usually occur as small patches rather than huge areas such as in the Great Australian Bight. The Australian continent is extremely dry, and there are no major rivers discharging terrigenous material to the southern coasts, so that the sediment type cannot be compared with that of most other continental shelves, which are mainly sand or mud).

Thus again data that are available do not suggest that there is a clear gradient of increasing species richness from shallow water to the deep sea; comparable areas of soft sediment habitat have similar numbers of species. Table 3 shows that there is only one recent quantitative survey from the deep sea examining many taxa, that of Grassle and Maciolek (1992). Other data (e.g. Hessler and Wilson, 1983; Poore and Wilson, 1997) suggest that Grassle and Maciolek's data are not representative of the deep sea as a whole. Thus there are too few data sets yet available to make general statements about deep-sea diversity.

Gage (1996) questioned whether one could make valid comparisons of the deep-sea data of Grassle and Maciolek with those of coastal areas. He stated that the deep-sea area sampled by Grassle and Maciolek was a single uniform habitat, whereas coastal samples (e.g. those of Gray, 1994) are invariably from a variety of different types of sediment. Gage argued that one cannot compare species richness of 
within habitat (deep-sea) samples with shallow water (between habitat) samples. Gray et al. (1998) countered by suggesting that along a $176 \mathrm{~km}$ transect of the deep sea the sediment and biological assemblages must vary so that both the deep sea and coastal samples are from between habitats. They further argue that it is still a valid question to ask whether there are more species per unit area in the deep sea compared with the coast irrespective of any variation between habitats. In summary, as with the southern hemisphere species richness gradient, there is no clear trend in increasing species richness from coasts to deep sea.

\section{Hypotheses concerning gradients in species richness}

From the above it is clear that there is a cline of increasing species richness from the Arctic to the tropics but it is as yet unclear whether or not a similar relationship occurs in the southern hemisphere. Very high species richness of corals, bivalves (and probably many other taxa) occurs in the Indonesian archipelago. Species richness decreases radially from this area both latitudinally and longitudinally. The deep sea has surprisingly high species richness, which may or may not be higher than coastal areas and thus hypotheses are needed to explain this. The key mechanisms suggested to explain these patterns of species richness are: biological interactions, area, energy-productivity, species ranges (Rapoport's Rule, Stevens 1989), the random boundary hypothesis, and historical (evolutionary) factors.

\section{Biological interactions}

The role of biological interactions as an explanation for the latitudinal gradient was popular in the 1960s and 1970s. Based on marine data Sanders (1968) suggested that in benign environments species competed with each other and the result was small non-overlapping niches with high numbers of species compared with harsher environments where species had to adapt more to the environment. Sanders used this explanation for the high species richness of the deep sea compared with that of the coasts and for the tropics compared with higher latitudes. However, others (Dayton and Hessler, 1977) argued that the gradient could equally be explained by predation/disturbance. The tropics (and deep sea), it was argued have higher numbers of predators/disturbers and keep prey populations low so that more species can co-occur.
These seemingly opposing views, were reconciled by Huston (1979) in his "general hypothesis of species diversity". However, few testable predictions came from these speculations. It is now widely believed that in terrestrial systems local species richness is largely determined by regional richness rather than by local biological interactions, (Ricklefs, 1987; Cornell, 1999; Loreau, 2000). Cornell and Karlson (1997) have shown for corals that there is indeed a strong correlation between local and regional species richness. I have plotted benthos data for the Norwegian continental shelf and a broadly similar relationship holds (Fig. 1). It is likely then that this relationship is a general one. If so this would imply that studies of biological interactions on local scales do not help understanding mechanisms controlling species richness (Lawton, 1999).

\section{The species-area hypothesis}

Williams (1964) cites a study by H.C. Watson from 1859 showing how in Britain the number of plant species increased as the area sampled increased. This log-log relationship has been found

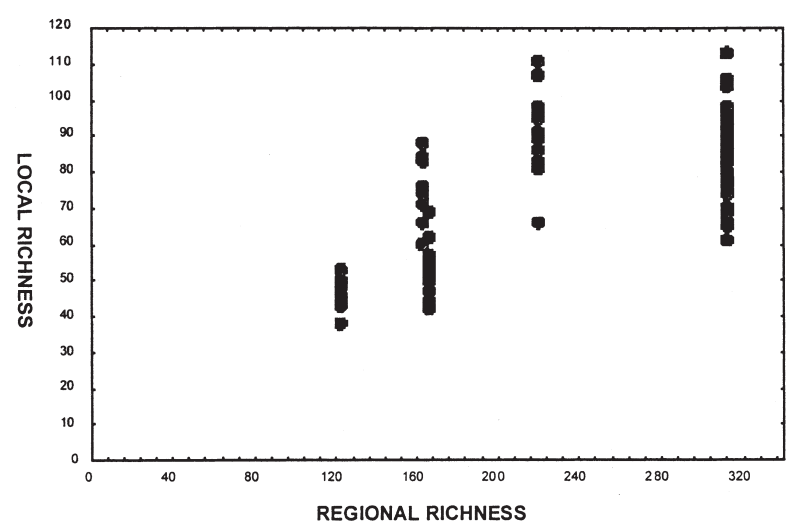

FIG. 1. - Relationship between local and regional species richness for Norwegian continental shelf, data from Gray (1994).

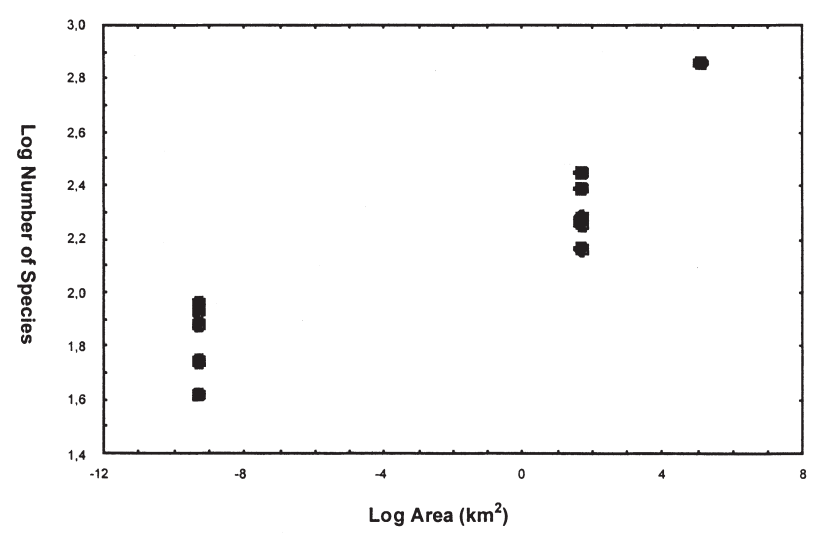

FIG. 2. - Species area relationship for Norwegian continental shelf benthos, data from Gray (1994). 
to apply to a wide variety of animals and plants. The form of the relationship was first deduced by Frank Preston, (1962), who called it the Arrhenius equation after the Swedish physicist who first derived this equation. The equation $S=c A^{z}$ where $S=$ number of species, $A$ is area and $c$ and $z$ are constants. This equation can be written as $\log S=z \log A+\log$ $c, \mathrm{z}$ being the slope of the species-area curve and log $c$ the intercept. It is important to remember that the species-area relationship applies to a variety of scales from small, often less than $1 \mathrm{~m}^{2}$ to very large, thousands of $\mathrm{km}^{2}$. (This relationship should not be confused with "collector's or species accumulation curves" that are plots of how species accumulate as sample size increases, but over one usually small spatial scale, e.g. species accumulation with successive samples).

The species-area relationship over large areas has been shown to be one of the most general found in ecology, (Rosenzweig, 1995). Yet there are few examples of marine data that have been plotted over large areas. Abele and Walters (1979) reanalysed Sanders (1968) data and showed convincingly that a simple species-area relationship following the classical Arrhenius curve held and was sufficient to account for the observed pattern of species richness. They concluded that on the basis of this relationship the deep sea is not extraordinarily species rich nor are estuaries and continental shelves species poor. Furthermore, they argued that there was no need to develop other more complex hypotheses (e.g. the stability-time hypothesis, Sanders 1968) as Occam's Razor should apply and a simple species-area relationship holds. Rohde (1978) has examined marine parasite data. I have plotted data for the benthos of Norwegian continental shelf and the classical Arrhenius equation holds, (Fig. 2). Thus such a relationship is likely to hold since it is a general rule for terrestrial systems.

Rosenzweig (1995) has championed the speciesarea relationship as the simplest explanation clarifying the patterns in species richness found. However, Rohde (1992) suggested that Rosenzweig's hypothesis, that tropical species richness was the greatest simply because on land the tropics covered the largest area, could not hold as the tropics did not have the largest area in his analysis. Rosenzweig and Sandlin (1997) give a convincing counter-argument, (see also Gaston, 1999).

Rosenzweig (1995 p 190) gives three arguments for the increase in number of species with area sampled. First, due to space/niche requirements a large area can contain more species than a small area, second a large area can contain more habitats and hence more species than a small area and third a large area can contain more individuals and therefore more species than a small area.

Abele and Walters (1979, Table 2, p. 118) showed that Sanders' data covered sediments ranging from $22 \%$ to $86.3 \%$ silt and from $6.5 \%$ to $35 \%$ clay with organic content varying from $0.33 \%$ to $6.7 \%$ organic carbon. Clearly Sanders original data on which the paradigms of marine biodiversity were erected were not from a uniform habitat, as claimed for example by Gage (1996), but from different sedimentary habitats. Thus Sanders data may not simply be a question of the different areas of the provinces that his samples represent, but rather that low species richness was found within a single habitat and high species richness is found where several habitats were covered. As yet there are few marine studies that examine the relationship between species richness and habitat heterogeneity in a quantitative way. In Bass Strait, Australia mean sediment grain size ranged from 0.3 to $0.9 \mathrm{~mm}$ and is remarkably uniform, yet one $0.1 \mathrm{~m}^{2}$ sample comprised 187 species and 12 out of 38 taken on one occasion comprised more than 100 species (Coleman 1997). Clearly habitat diversity is not essential for high species richness.

The third hypothesis proposed to explain the species-area relationship is that larger areas have a greater number of individuals and hence species. With larger numbers of individuals it is suggested that there are lower extinction rates (e.g. birds on British islands, Rosenzweig, 1995). Gray et al. (1998) found no evidence that there are fewer individuals per species in deep sea than in coastal areas. With the exception of this observation there are no marine studies that have tested this hypothesis. Recent terrestrial data (Gaston, 1998) suggests that numbers of individuals increase at a faster rate than the area over which they are distributed. This means that more widely distributed species not only tend to have larger numbers of individuals but also tend to occur at higher local densities. Whether this is also true for marine systems remains to be tested.

In relation to the latitudinal gradient and speciesarea Rosenzweig, (1995) makes a much broader suggestion, that tropical terrestrial habitats occupy a greater area compared with higher latitudes and thus from the species-area relationship more species should be found in the tropics. However, Rohde (1997) showed that the area of the tropics is not 
greater than that in higher latitudes, thus undermining Rosenzweig's hypothesis. Rodhe (1997) suggests that in the marine domain the areas of tropics to temperate and high latitudes vary with ocean, but overall there is not a greater area within the tropics.

Roy et al. (1998) plotted the area of $5^{\circ}$ latitudinal segments against species richness for prosobranch gastropod snails. This study compared species richness collected within latitudinal boundaries from a wide variety of different habitats such as soft sediments, sea-grasses, mangroves, hard substrata and corals for geographical provinces in a comparative manner. Although they claimed that that there was no relationship between area and species richness for the continental shelves of the east and west coasts of N. America, they did not test whether or not there was a species area relationship at different spatial scales over the whole area studied. Overall however, they found that the greatest areas were at high latitudes whereas the greatest species richness occurred between $20^{\circ} \mathrm{N}$ and $30^{\circ} \mathrm{N}$ not in the tropics.

Lyons and Willig (1999) have developed a scaledependency approach, which allows separation of area and latitude effects on species richness. For bats and marsupials only latitude was significant. Thus again area per se does not seem to be important.

In summary species-area relationships have been extremely poorly studied in the marine environment. With so few data explicit tests of the hypotheses proposed by Rosenzweig have not been made. It seems unlikely, however, that the reasons for the extremely high tropical species richness, particularly within the S. China-Indonesia-N. Australia province is related to area.

\section{The energy-productivity hypothesis}

The energy-productivity hypothesis is due to Wright (1983) who extended the species-area hypothesis to encompass energy as a more direct controlling factor on species richness than area alone. Briefly the hypothesis states that the available energy is maximal in the tropics and shows a decline polewards and this gradient is also shown in species richness. The correlates of energy are measures of heat such as mean annual temperature, mean summer temperature, seasurface temperature or evapotranspiration. A number of data sets conform to this theory such as butterflies and birds in the British Isles (Turner et al. 1987, 1988; Fraser and Currie, 1996). Gaston (2000) has recently reviewed this topic.
Roy et al. (1998) found a clear correlation with sea surface temperature, a surrogate for energy input, and thus favour this as an explanation for the latitudinal gradient found in prosobranch molluscs in the northern hemisphere. Yet as Lambshead (1993) points out there may not be a gradient of decreasing productivity from tropics to poles. Primary productivity is closely coupled to secondary production in the tropics so that there is little flux to the seabed. Moving polewards the primary bloom becomes more decoupled from the grazing bloom so that much phytoplankton settles to the seabed. The settlement of material is however, highly patchy and patchiness of food is greatest in polar areas, (Grassle, 1989). This patchiness should over evolutionary time lead to higher, not lower, species richness, (Lambshead, 1993). Rosenzweig (1995) shows clearly that the relationship between species richness and productivity is not linear but shows a maximum at intermediate values of productivity in many different ecological systems. It is well known that in eutrophic marine sediment systems species richness is reduced (Pearson and Rosenberg, 1978). However, again a word of caution eutrophication acts over ecological scales not evolutionary scales. In conclusion explicit tests of the energy-area relationship need to be proposed before any conclusions can be drawn concerning the energy-area hypothesis applied to marine data.

\section{The species range hypothesis}

(Rapoport's rule, 1982)

Rapoport's rule (Rapoport, 1994) suggests that there is a decrease in species range lengths towards lower latitudes and thus more species are able to coexist. It is claimed that a wide variety of species groups show such a trend, (Stevens, 1989) but there are many data sets that do not follow the rule (see Chown and Gaston 2000 for a review.) Roy et al. (1998) showed that the rule did not hold for prosobranch molluscs since along both coasts median latitudinal ranges of species were greatest, not in high but at low latitudes. Thus there seems to be little general support for Rapoport's rule with recent data, but see Taylor and Gaines (1999).

\section{Random boundary hypothesis}

A more recent explanation for the latitudinal gradient is a model that assumes no environmental gradients but merely a random association between the size and midpoint of the geographical range of 
species, (Colwell and Hurt, 1994; Colwell and Lees, 2000). A peak of species richness in the tropics is predicted since the latitudinal range of a species is bound to the north and south. The bounds may be physical such as mountain ranges or biological such as critical temperatures or precipitation. A species with a range midpoint midway between the bounds can extend a long way, whereas one near the bound can extend only a limited way. As the tropics have a large area either side of the equator more species are packed within their bounds at low latitudes. Colwell and Lees (2000) present convincing data, but again no studies have been made with marine data.

\section{The evolutionary age hypothesis}

One might expect from first principles that the earth's geological history was important in determining species richness patterns. There are two key processes that control species richness over evolutionary time, speciation and extinction. It is postulated that speciation rates are higher in tropical regions and decrease polewards, e.g. the comparison between angiosperm species richness in Asia compared with Europe and N. America, (Stenseth, 1984; Latham and Ricklefs, 1993). However, over geological time it is known that $90 \%$ of all the species that have ever lived have become extinct. Thus interpreting modern patterns on the basis of geological history is difficult, (Kerr and Currie, 1999).

One prediction that can be tested, however, is that the mean ages of taxa should differ among regions of high and low richness. Several authors argue that centres of species richness are also evolutionary centres where new species evolve and from which they then spread to marginal areas. The prediction is then that such areas should have a high proportion of young taxa. Stehli and Wells (1971) compiled data on corals and found that this prediction was upheld. However, Ricklefs and Schluter (1993) proposed that areas of high richness should have old and new taxa whereas marginal areas should only have young taxa since species are colonising these areas. Crame's (2000) comprehensive analyses of bivalve data shows clearly that speciation rates are higher in tropical areas, but he suggests there is no evidence that extinction rates vary with latitude.

There is good evidence that the fauna of the Norwegian Sea has low species richness, high endemism, low affinity with the fauna of the North Atlantic deep basin and low speciation rates (Dahl, 1979; Bouchet and Waren, 1979). This area is geologically young, 2 million years, and isolated. Thus evolutionary time is a key variable that needs more consideration in the latitudinal species richness debate.

\section{Conclusions on hypotheses for patterns of species richness}

Research on species richness has in the marine domain has concentrated on describing patterns of species richness. The cline from the Arctic to tropics has been established in the Atlantic and Pacific coast of N. America (Rex et al. 1993; Roy et al. 1996, 1998). Yet we still do not know whether there is a cline of increasing species richness from poles to tropics in the southern hemisphere. Crame's (2000) study suggests that there is likely to be high richness in the biogeographical provinces in Australia. It is difficult to talk of a cline when there are three continents to consider, Antarctica, Australia and Asia. All of these are old and have been free from glaciation for much longer periods than the Northern hemisphere. It is likely that there will be complex patterns of species richness in the southern hemisphere, as Crame (2000) has suggested. Studies along the coasts of Africa and S. America are urgently needed.

There seems little doubt that speciation rates are higher in the tropics and particularly in the epicentre for marine tropical development in the Indonesian archipelago and neighbouring regions. The current view, as exemplified by Crame (2000) is that species are radiating from this region, and this explains the clines of species richness decreasing radially from this region (in a north-south latitudinal and an east-west, longitudinal pattern). As with many hypotheses in ecology they are not mutually exclusive. It is likely that a combination of many factors will prove to be the key to understanding. For terrestrial data the energyproductivity hypothesis is perhaps the one receiving most support. Yet for marine data Roy et al.'s. (1996, 1998) data show that temperature was the best correlated variable. Whether this is a direct physical effect, where higher temperatures are somehow associated with higher speciation rates and/or lower extinction rates or temperature simply correlates with energy/productivity has not been studied.

\section{FUTURE ISSUES}

The primary focus on marine diversity in recent years has been to estimate how many undiscovered species there are in the deep sea. Grassle and Maci- 
olek (1992) estimated 10 million, May (1993) countered with 500,000, whilst Briggs (1993) called Grassle and Maciolek's estimates "statistical legerdemain". Lambshead (1995) argued that if meiofauna were to be included the figure was more like 100 million undiscovered species from the deep sea! Grassle and Maciolek's estimates are no more statistical legerdemain than were Erwin's (1982, 1988), much quoted and debated, estimates of tropical diversity based on samples of beetles from a few tropical trees. All of us surely agree that we simply do not have enough data on which to make valid estimates of the total number of species that might be found in the deep sea (or on the continental shelves) and more data are urgently needed. It is a sad fact that we know more about the backside of the moon than we do about the bottom of the deep sea!

Yet do we know enough about coastal biodiversity? Whereas the deep sea is a relatively uniform habitat covered largely by soft sediments, coasts include coral reefs, mangrove forests, kelp forests, sea-grass meadows, salt marshes, estuaries, intertidal sand and mud flats, rocky inter- and sub-tidal areas and the large expanse of continental shelf sediments, (from where most of the commercial living marine resources are obtained). We have very poor knowledge of the patterns of species richness especially at different spatial scales and from tropical regions. With this large variety of habitats, the world's coastal zones surely must have higher species richness than the deep oceans. This hypothesis is strengthened by recent data, which suggests that the marine tropical region of the Indonesian archipelago is the centre for speciation in the sea and species are radiating out from this region including the deep sea, (Crame, 2000). Another major argument for devoting more effort to understanding coastal diversity is that the threats to coastal biodiversity from habitat loss and degradation, from fishing (especially trawling), from eutrophication and from introduced species, (Gray, 1997). The threats are many and increasing in magnitude. Thus, the top priority for marine diversity research is to gain more knowledge about coastal diversity and how it best can be conserved.

Perhaps the most logical place to begin is with a severely neglected topic that of describing the spatial scales over which species richness and diversity occur. Measurement of the spatial scales of assemblages (from point through sample to large areas and biogeographical provinces Gray, 2000), of habitats and landscapes and how these different scales relate to species richness are topics that are attracting increasing attention (Thrush, 1996, 1997; Zajac, 1999). A variety of new technologies, such as sidescan sonar, acoustic sediment classification systems, digital UW cameras, REMOTS sediment profiler etc. are giving new insights. We need to relate spatial scales of habitats and landscapes to patterns of species richness. Here we need new models for estimation of the total number of species in given areas. Colwell's Estimates programme (Colwell and Coddington, 1996) is one approach, and there has been an upsurge in interest in models of species abundances (Tokeshi, 1992; Hill, 1997; Smith and Wilson, 1997).

Related to this topic is the problem of rareness. Acceptance of the lognormal distribution as a description of the distribution of individuals among species implies that most species are rare, occurring at low abundances per sample unit. A recent study of rarity in Amazonian forest trees documented precisely how hundreds of tropical trees are rare, (Pitman et al., 1999). This study found that $31 \%$ of the species were represented by single individuals and of these $45 \%$ occurred in only one of the 21 plots studied. Yet the sparse populations were distributed across a wide range of habitats. Thus the results show that tropical trees are not habitat specialists as previously thought. In addition the processes that control the persistence of tree populations within a region operate over much larger spatial scales and longer time periods, (Ricklefs, 2000). Our studies of an extensive data set from the Norwegian continental shelf show that marine data is similar to Pitman's (Ellingsen, unpubl.)

Knowledge of species geographical ranges has provided important information for a variety of new ideas on patterns controlling species diversity. For example, tests of the species : area model and Rapoport's Rule, relate range size of tropical species to those of higher latitudes. Another aspect of the species : area relationship is whether or not there are positive relationships between range size and speciation and extinction, (Chown and Gaston, 2000). Yet with the exception of the studies of Roy et al. (1996, 1998) on gastropods, Crame (2000) on bivalves and Cornell and Karlson (1997) on corals, there are few marine data covering species ranges.

One of the major questions facing biodiversity in general is are all the species in a given assemblage needed for efficient functioning of the system? The suggestion has often been made that most species are rare and contribute little to the overall function- 
ing of the system such as primary production, nutrient regeneration etc. Naeem et al. (1995) and Tilman and Downing (1994) showed in experiments in a laboratory system and in field experiments respectively that terrestrial systems functioned better with more species. The experiments have, however been heavily criticised (Huston, 1997, Grime, 1997) since different species and sizes of organisms were used in the high and low species systems such that they were not comparable. The debate heated up even more with the publication of the results of a large European experiment BIODEPTH, (Hector et al., 1999). The authors claimed that in this study there was an overall log-linear reduction in biomass with loss of species in European grasslands sampled at eight sites. Huston et al. (2000) argued that the results could be explained more simply as a sampling effect. That is that as more species were added to the assemblage it was more likely that one of the new species would be highly productive thus increasing the overall productivity of the plot. Therefore, the major issue is not so much whether or not numbers of species are important for maintenance of system functioning but rather it is which species are present that is important. My personal feeling is that species identity is the key issue rather than numbers of species per se. If this is true then most species are redundant and contribute little to system function. There are surprisingly few marine studies that have tackled this issue, (but see Duarte, 2000).

Snelgrove et al. (1997) have reviewed the key ecological processes that are carried out in marine sediments. Primarily microorganisms carry many of these processes, such as carbon, nitrogen and sulphur cycling, out. Determining the interactions between macro- and meiofauna and bacteria over different spatial and temporal scales is a major task. Such experimental studies are only just beginning and need to be linked to structural redundancy.

Whether diversity is controlled by local or by regional processes is a major theme of ecological research (Lawton, 1999). Although different levels of community control clearly exist (Latham and Ricklefs, 1997; Silvertown et al., 1999), evidence from diverse systems is now firmly in favour of regional control (Cornell and Lawton, 1992; Caley and Schluter, 1997; Karlson and Cornell, 1999; Cornell, 1999). Cornell and Karlson (1999) studied corals reefs and this is the only marine system that has been explored so far. If Lawton (1999) is correct that it is the regional species pool that determines local species richness then research efforts should be directed at understanding the regional pool, it's origin and maintenance using genetic tools, rather than concentrating on biological interactions at local scales as has been the marine tradition.

Finally marine diversity research must be relevant to the needs of the managers. At a recent meeting of the European Unions Marine Science and Technology (MAST) research programmes in Lisbon, 1998, the Director General for Environmental Research Dr C. Patermann listed what he, as a political manager of research, felt were the key questions for biodiversity. These are:

-what are the causes, the rate and the extent of biodiversity loss?

-what are the critical thresholds for loss of biodiversity, the relative importance of different species, and the feasible options for both the monetary and non-monetary valuation of biodiversity?

-how can society meet the twin objectives of biodiversity preservation and economic utilisation?

-what are the trends and scenarios in the evolution of the biological diversity and its interactions with the other ecosystem factors including the human element?

Most developed countries are signatories of the Convention on Biodiversity (CBD). In signing they are committed to undertaking inventories of biodiversity and the status of biodiversity. Few countries have done this for their coasts and continental shelf areas. The CBD has talked a lot, but little practical has appeared to help stem the tide of biodiversity loss in coastal and shelf areas. So how can we answer the needs of the politicians and managers as formulated by Patermann and envisaged in the CBD?

The causes of biodiversity loss are relatively easy to see. The destruction of coral reefs is well documented and there are few countries that have more than $30 \%$ of the mangroves that were present in the 1950's. Changed sediment loads from rivers, increase from up-river deforestation or decreased caused by damming, have led to huge changes in coastal ecosystems. The development of the tourist industry is also a major factor in coastal habitat destruction. In Europe there are few estuaries that have not been "reclaimed" (i.e. their wetland areas have been destroyed) and coastal "development" is a misnomer for destruction of marine habitats. For large areas of the coast it is relatively easy to document these changes by aerial photography and use of GIS. Subtidally documenting the changes caused by fishing and especially trawling has been done using 
video. These show modern beam and otter trawls scraping the sea bed to tens of centimetres deep, leaving behind sediments devoid of rocks and epifauna that were common only a decade or so ago. Off the Canadian coast and along the shelf of Norway the destruction by trawlers of the slow growing and extensive beds of cold-water corals (Lophelia) is scandalous. Destruction of these habitats almost certainly will lead to negative impacts on fish recruitment, which will require new approaches across a variety of scales from small, a few meters to hundreds of kilometres.

In a marine context when lay persons ask us for information on the relative importance of individual species they are usually thinking of seals, birds and fish species. Britain has a total of 193 species of breeding birds, (Rosenzweig, 1995) and with the large number of amateur ornithologists it is a relatively simple to measure change in all the species. This is not so for the marine environment. The coast of Norway has at least 4,500 species of large marine organisms (Brattegard and Holthe, 1997). It is clearly impractical to assess the importance of all of these. Ideas about "keystone" species (Paine, 1974) have changed greatly in recent years. The "classical" examples of a few years ago such as the lobsterurchin-kelp forest system (Mann, 1982) has been shown to be much more complex (Pringle, 1986; Elner and Vadas, 1990). The kelp forest along the coast of northern Norway was decimated over 1,500 $\mathrm{km}$ and sea urchin numbers were high. Complex explanations included conservation of seals led to a seal explosion, seals no longer ate catfish, which in turn released urchins from control and they ate the kelp. There was no evidence for this hypothesis and it is now felt that the kelp-urchin link is probably physically controlled, but in a complex way not fully understood, Thus it is generally accepted that there are in fact relatively few clear examples of species which control whole systems, the "keystone" species idea.

Conservation of individual species in coastal and continental areas is impractical, save for large species or species where the biology is well known. A more realistic approach is to conserve habitats, since if one conserves the habitat one conserves the species contained therein. The problem is that defining what is a habitat is not a simple task. Whilst we all agree that seagrass beds are different from mangrove forests things are not so straightforward for sediments. Sediments tend to grade one into another with the result that assemblages do the same and there are only rarely clear boundaries between assemblages. Assemblage and patch dynamics and interactions need to be better understood and modelled.

Conservation strategies are usually compromises between what we know and what is practical in a socio-economic context. The dearth of taxonomic expertise for making inventories of marine biodiversity has been stated many times before (Solbrig, 1991). Time is not on our side and we cannot hope to make inventories of all the species that occur in many areas that are threatened. Some success has been had in assessing terrestrial biodiversity using parataxonomists (Oliver and Beattie, 1993). Nonspecialists are trained to distinguish between but not to identify species. Inventories done in this way were accurate enough to make good estimates of the biodiversity of an area. Again these methods have not been tried out in the marine domain, but with the increasing rate of loss of habitats in tropical coastal areas such methods are urgently needed.

Another method is to use surrogates for full species inventories, so-called rapid-assessment techniques. A recent example again from terrestrial systems is from data on 47 forests in Uganda (Howard, et al., 1998). Here species inventories were available for many taxa, and the hypothesis was tested that some groups, birds, moths or butterflies could be used to make assessments of which forests or areas of forest should be conserved. Using a simple algorithm it was found that bird species richness alone gave reliable data on which forest conservation strategies could be made. Similar tests are urgently needed in coastal and continental shelf areas, particularly in the tropics.

Finally, the value of natural coastal systems, has been assessed by Constanza et al. (1996). Their figures are surprisingly high and although only preliminary estimates, they show that intact systems have high intrinsic value. Whether or not these values are realistic or not will only be borne out by further calculations. There is clearly an urgent need for social and natural scientists to combine to give better assessments of the value of intact biodiversity in coastal systems on local and regional scales. Only when these data are available will we be able to give the politicians the answers they need on the balance between needs for conservation against the pressures for utilisation of coastal systems. One disturbing aspect is that with the globalisation of the world economy the research priorities of most developed countries are directed to wealth creation and provision of new jobs. I believe that it is far more impor- 
tant to protect the remaining biodiversity that we have and that wealth protection is far more important than wealth creation.

The challenges are there and we know what needs to be done but financial support is lacking and biodiversity is not among the highest priorities for funding. The CBD has moved extremely slowly from its signing and has yet to do anything practical in a co-ordinated way. This will become a lost opportunity unless scientists are prepared to engage more in the policy aspects of biodiversity and its management.

\section{REFERENCES}

Abele, L. and J. Walters. - 1979. Marine benthic diversity: a critique and alternative explanation. J. Biogeogr., 6: 115-126

Begon, M., J.L. Harper and C.R. Townsend. - 1990. Ecology: individuals, populations and communities. Oxford: Blackwell Scientific Publications.

Boucher, G. and P.J.D. Lambshead. - 1995. Marine nematode ecological biodiversity in samples from temperate, tropical and deep-sea regions. Conserv. Biol., 9: 1594-1604.

Bouchet, P. and A. Waren. - 1979. The abyssal molluscan fauna of the Norwegian Sea and its relation to other faunas. Sarsia 64: 211-243.

Brattegard, T. and T. Holthe. - 1997. Distribution of marine, benthic macro-organisms in Norway. A tabulated catalogue. Preliminary edition. Research Report No. 1991-1 Directorate for Nature Management, Trondheim, Norway. 409 pp.

Briggs, J.C. - 1991 Global species diversity. J. Nat. Hist., 25: 14031406

Briggs, J.C. - 1994. Species diversity: Land and sea compared. Syst. Biol. 43: 130-135.

Briggs, J.C. - 1995. Global Biogeography. Elsevier, Amsterdam.

Brown, A.C. and A. Maclachlan. - 1990. Ecology of Sandy Shores. Amsterdam, Elsevier.

Caley M.J. and D. Schluter. - 1997. The relationship between local and regional diversity. Ecology 78: 70-80.

Chown, S.L. and K.J. Gaston. - 2000. Areas, cradles and museums: the latitudinal gradient in species rchness. Trends Ecol. Evol., 15: $311-315$

Clarke, A. - 1992. Is there a latitudinal diversity cline in the sea? Trends Ecol. Evol., 7: 286-287.

Coleman, N., A.S.H. Gason and G.C.B. Poore. - 1997. High species richness in the shallow marine waters of south-east Australia. Mar. Ecol. Progr. Ser., 154: 17-26

Coleman, N.C., W. Cuff, M. Drummond and J.D. Kudenov. - 1978. A quantitative survey of the macrobenthos of Western Port, Victoria. Austr. J. Mar. Fresh. Res., 29: 445-466

Coleman, N., A. Gason and G.C.B. Poore. - 1999. High species richness in the shallow marine waters of south-east Australia. Mar. Ecol. Progr. Ser., 154: 17-26.

Colwell, R.K. and J.A. Coddington. - 1994. Estimating terrestrial biodiversity through extrapolation. Phil. Trans. Roy. Soc. London, Series B 345: 101-118.

Colwell, R.K. and D.C. Lees. - 2000. The mid-domain effect: geometric constraints on the geography of species ruchness. Trends Ecol. Evol., 15: 70-76.

Colwell, R.K. and G.C. Hurt. - 1994. Nonbiological gradients in species richness and a spurious Rapoport effect. Am. Nat., 144: 570-595.

Cornell, H.V. - 1999. Unsaturation and regional influences on species richness in ecological communities: a review of the evidence. Ecosiences 6: 303-315.

Cornell, H.V. and R.H. Karlson. - 1996. Species richness of reefbuilding corals determined by local and regional processes. $J$. Anim. Ecol., 65: 233-241.

Cornell, H.V. and J.H. Lawton. - 1992. Species interactions, local and regional processes and limits to the richness of ecological communities: a theoretical perspective. J. Anim. Ecol., 62: 1-12.

Costanza, R. et al. 1997 The value of the world' ecosystem services and natural capital. Nature 387: 253-260

Cowling, R.M., G.E. Gibbs Russell, M.T. Hoffman and C. HiltonTaylor. - 1992. Patterns of plant species diversity in southern Africa. In: B.J. Huntley (ed.), Biotic Diversity in southern Africa: Concepts and Conservation. pp19-.50. Cape Town, Oxford University Press.

Crame, J.A. - 2000. Evolution of taxonomic diversity gradients in the marine realm: evidence from the composition of recent bivalve faunas. Paleobiology, 26: 188-214

Dahl, E. - 1979. Amphipoda Gammaridea from the deep Norwegian Sea: A preliminary report. Sarsia 64: 57-59.

Dayton, P.K. and R.R. Hessler. - 1972. Role of biological disturbance in maintaining diversity in the deep sea. Deep-Sea Res., 19: 199-208.

Elner, R.W. and R.L. Vadas. - 1990. Inference in ecology: the seaurchin phenomenon in the northwestern Atlantic. Am. Nat., 136: $108-125$.

Erwin, T.L. - 1982. Tropical forests: their richness in Coleoptera and other arthropod species. Coleopter. Bull., 36: 74-75.

Erwin, T.L. - 1988. The tropical forest canopy: the heart of biotic diversity. In: E.O. Wilson, (ed.), Biodiversity, pp. 123-129 National Academy Press, Washington DC.

Etter, R.J. and J.F. Grassle. - 1992. Patterns of species diversity in the deep-sea as a function of sediment particle size. Nature, 360: $576-578$.

Fager, EW. - 1972. Diversity: A sampling study. Am. Nat., 106: 293-310.

Fraser, R.H. and DJ. Currie. - 1996. The species richness-energy hypothesis in a system where historical factors are thought to prevail: coral reefs. Am. Nat., 148: 138-154.

Gage, J.D. - 1973. Community structre of the benthos in Scottish sealochs. I. Introduction and species diversity. Mar. Biol., 14: 281-297.

Gage, J.D. - 1996. Why are there so many species in deep-sea sediments? J. Exper. Mar. Biol. Ecol., 200: 257-286.

Gage, J.D. and R.M. May. - 1992. A dip into the deep seas. Nature 365: 609-610.

Gage, J.D. and P.K. Tyler. - 1992. Deep-sea biology: a natural history of organisms at the deep sea floor. Cambridge, Cambridge University Press.

Gaston, KJ. - 1998. Rarity as double jeopardy. Nature, 394: 229-230.

Gaston, K.J. - 2000. Global patterns in diversity. Nature, 405: 220-233.

Grassle, J.F. - 1989. Species diversity in deep-sea communities. Trends Ecol. Evol., 4: 12-15.

Grassle, J.F. - 1991. Deep-sea benthic biodiversity. Bioscience 41: 464-469

Grassle, J.F. and N.J. Maciolek. - 1992. Deep-sea species richness: regional and local diversity estimates from quantitative bottom samples. Am. Nat., 139: 313-341.

Gray, J.S. - 1994. Is the deep sea really so diverse? Species diversity from the Norwegian continental shelf. Mar. Ecol. Progr. Ser., 112: 205-209.

Gray, J.S. - 1997. Gradients of marine biodiversity. In: R. Ormond, J. Gage and J.F. Grassle (eds.), Marine Biodiversity: Patterns and Processes, pp. 18-34. Cambridge, Cambridge Univ. Press.

Gray, J.S., G.C.B. Poore, K.I. Ugland, R.S. Wilson, F. Olsgard and $\emptyset$. Johannessen. - 1997. Coastal and deep-sea benthic diversities compared. Mar. Ecol. Progr. Ser., 159: 97-103.

Gray, J.S. - 2000. The measurement of species diversity: an example from the continental shelf of Norway. J. Exper. Mar. Biol. Ecol., 250: 23-49.

Hector, A.., B. Schmid, C. Beierkuhnlein, M.C. Caldeira, M. Diemer, P.G. Dimitrakopoulos, J.A. Finn, H. Freitas, P.S. Giller, J. Good, R. Harris, P. Högberg, K. Huss-Danell, J. Joshi, A. Jumpponen, C. Körner, P.W. Leadley, M. Loreau, A. Minns, C.P.H. Mulder, G. O’Donovan, S.J. Otway, J.S. Pereira, A. Prinz, D.J. Read, M. Scherer-Lorenzen, E.-D. Schulze, A.-S. D. Siamantziouras, E.M. Spehn, A.C. Terry, A.Y. Troumbis, F.I. Woodward, S. Yachi and J. H. Lawton. - 1999. Plant diversity and productivity experiments in European grasslands. Science 286: 1123-1127

Hessler, R.R. and P.A. Jumars. - 1974. Abyssal community analysis from replicate box cores in the Central North Pacific. DeepSea Res., 14: 65-78.

Hessler, R.R. and H.L. Sanders. - 1967. Faunal diversity in the deep 
sea. Deep-Sea Res.,. 7: 65-78.

Hessler, R.R. and G.D.F. Wilson. - 1983. The origin and biogeography of malacostracan crustaceans in the deep sea. In: R.W. Sims, J.H. Price and P.E.S. Whalley (eds.), Evolution, Time and Space: The Emergenece of the Biosphere, pp 227-254. New York, Academic Press.

Hill, M.O. - 1997. An evenness statistic based on the abundanceweighted variance of species proportions. Oikos 79: 413-416.

Hopper, S.D. - 1992. Biogeographical aspects of speciation in the soutwest Australian flora. Ann. Rev. Ecol. Syst., 10: 399-422.

Howard, P.C., P. Viskanic, T.R.B. Danenport, F.W. Kigenyi, M Baltzer, C.J. Dickinson, J.S. Lwwanga, R.A. Mathews and A. Balmford. - 1998. Complementarity and the use of indicator groups for reserve selection in Uganda. Nature, 394: 472-475.

Hurlbert, S.H. - 1971. The non-concept of species diversity: a critique and alternative parameters. Ecology, 52: 577-585.

Huston, M.A. - 1979.A general hypothesis of species diversity. Am Nat., 113: 81-101

Huston, M. - 1994. Biological diversity: the coexistence of species in changing landscapes. Cambridge, Cambridge University Press.

Huston, M.A. - 1997. Hidden treatments in ecological experiments: re-evaluating the ecosystem function of biodiversity. Oecologia, 110: 449-460

Huston, M.A, L.W. Aarssen, M.P. Austin, B.S. Cade, J.D. Fridley, E Garnier, J.P. Grime, J. Hodgson, W.K. Lauenroth, K. Thompson, J.H. Vandermeer and D.A. Wardle. - 2000. No consistent effect of plant diversity on productivity. Science, 289: 1255

Jumars, P.A. - 1976. Deep-sea species diversity: does it have a characteristic scale? J. Mar. Res., 25: 217-246.

Kendall, M.A. and M. Aschan. - 1993. Latitudinal gradients in the structure of macrobenthos communities: a comparison of Arctic, temperate and tropical sites. J. Exper. Mar. Biol. Ecol., 172 157-169.

Kerr, J.T. and D.J. Currie. - 1999. The relative importance of evolutionary and environmental controls on broad-scale patterns of species richness in North America. Ecosciences, 6: 329-337.

Lambshead, P.J.D. - 1993. Recent developments in marine benthic biodiversity research. Oceanis, 19: 5-24

Latham, R.E. and R.E. Ricklefs. - 1993. Global patterns of tree species richness in moist forests: energy-diversity theory does not account for variation in species richness. Oikos, 67: 325-333.

Lawton, J.H. - 1999. Are there general rules in ecology? Oikos, 84: 177-192.

Levinton, J.S. - 1995. Marine biology. Function, biodiversity, ecology. New York, Oxford University Press.

Loreau, M. -2000 . Are communities saturated? On the relationship between $\alpha, \beta$, and $\gamma$, diversity. Ecol. Letters, 3: 73-76.

Lyons S.K and M.R Willig. - 1999. A hemispheric assessment of scale dependence in latitudinal gradients of species richness. Ecology, 80: 2483-2491.

Mann, K.H. - 1982. Kelp, sea-urchins and predation: a review of strong interactions in the rocky sublittoral system of eastern Canada. Netherl. J. Sea Res., 16: 414-423.

Marchant, N. - 1991. The vascular flora of South West Australia. $16^{\text {th }}$ Biennial Conference Association of Societies for Growing Australian Plants, pp. 16-18. Perth.

May, R.M. - 1992. Bottoms up for the oceans. Nature, 357: 278-279.

Naeem, S., L.J. Thompson, S.P. Lawler, J.H. Lawton and R.M. Woodfin. - 1995 Empirical-evidence that declining speciesdiversity may alter the performance of terrestrial ecosystems Philos. Trans. Roy. Soc. London, Series B 347: 249-262

Oliver, I. and A.J. Beattie. - 1992. A possible method for the rapid assessment of biodiversity. Conserv. Biol., 7: 562-568.

Olsgard, F. and J.S. Gray. - 1995. A comprehensive analysis of the effects of offshore oil and gas expoloration and production on the benthic communities of the Norwegian continental shelf. Mar. Ecol. Progr. Ser., 122: 277-306.

Paine, R.T. - 1974. Intertidal community structure: experimental studies on the relationships between a dominant competitor and its principal predator. Oecologia, 15: 93-120.

Paterson, G. - 1993.

Pearson, T.H. - 1970. The benthic ecology of Loch Linnhe and Loch Eil, a sea-loch system on the west coast of Scotland. I. The physical environment and the distribution of the macrobenthoc fauna. J. Exper. Mar. Biol. Ecol., 5: 1-34.

Pearson, T.H. and R. Rosenberg. - 1978. Macrobenthic succession in relation to organic enrichment and pollution of the marine environment. Oceanogr. Mar. Biol. Ann. Rev., 16: 229-311.

Pitman, N.C.A., J. Terborough, M.R. Silman and P. Nunez. - 1999. Tree species distribution in an upper Amazonian forest. Ecology, 80, 2651-2661.

Poore, G.C.B, S.F. Rainer, R.B. Spies and E. Ward. - 1975. The zoobenthos program in Port Phillip Bay, 1969-73. Fisheries and Wildlife Papers of Victoria 7: 1-78.

Poore, G.C.B., J. Just and B.F. Cohen. - 1994. Composition and diversity of Crustacea, Isopoda of the southeastern Australian continental slope. Deep-Sea Res., 41: 677-693.

Poore, G.C.B. and G.D.F. Wilson. - 1993. Marine species richness. Nature 361: 597-598.

Preston F.W. - 1962 The canonical distribution of commonness and rarity. Ecology 43, 185-215.

Pringle, J.D. - 1986. A review of urchin/macroalgal associations with a synthesis for nearshore, eastern Canadian waters. Monogr. Biol. 4: 191-218.

Rapoport, E.H. - 1982. Areography. Geographic strategies of species. Oxford, Pergamon Press.

Rapoport, E.H. - 1994. Remarks on marine and continental biogeography: an aerographical viewpoint. Philos. Trans. Roy. Soc. London, Series B 343: 71-78.

Rex, M.A. - 1973. Deep-sea species diversity: decreased gastropod diversity at abyssal depths. Science, 181: 1051-1053.

Rex, M.A.. - 1983. Geographic patterns of species diversity in deep-sea benthos. In: G.T. Rowe (ed.), The Seas, vol. 8: 453472, New York John Wiley and Sons.

Rex, M.A., C.T. Stuart, R.R. Hessler, J.A.. Allen, H.L. Sanders and G.D.F. Wilson. - 1993. Global-scale patterns of species diversity in the deep-sea benthos. Nature, 365: 636-639

Ricklefs, R.E. - 1987. Community diversity: The relative roles of local and regional processes. Science, 235: 167-171.

Ricklefs, R.E. - 2000. Rarity and diversity in Amazonian forest tress. Trends Ecol. Evol., 15, 83-84.

Ricklefs, R.E. and D. Schluter. - 1993. Species diversity: regional and historical influences. In: R.E. Ricklefs and D. Schluter (eds.). Species diversity in ecological communities, pp. 350363. Univ. Chicago Press.

Rohde, K. - 1978. Latitudinal differences in host specificity of marine Monogenea and Digenea. Mar. Biol., 47: 125-134.

Rohde, K. - 1992. Latitudinal gradients in species diversity the search for the primary cause. Oikos, 65: 314-327.

Rohde, K. - 1997. The larger area of the tropics does not explain latitudinal gradients in species diversity. Oikos, 79: 169-172.

Rosenzweig, M.L. - 1995. Species diversity in space and time. Cambridge U.P. 436 pp.

Rosenzweig, M.L. and E.A. Sandlin. - 1997. Species diversity and latitude: listening to area's signal. Oikos, 80, 172-176.

Roy, K., D. Jablonski and J.W. Valentine. - 1996. Higher taxa in biodiversity studies: patterns from eastern Pacific marine molluscs. Philos. Trans. Roy. Soc. London, Series B 351: 1605-1613.

Roy, K., D. Jablonski, J.W. Valentine and G. Rosenberg. - 1998. Marine latitudinal diversity gradients: tests of causal hypotheses. Proc. Natl. Acad. Sci. USA, 95: 3699-3702.

Sanders, H.L. - 1968. Marine benthic diversity: a comparative study. Am. Nat., 102: 243-282.

Sanders, H.L. - 1969. Benthic marine diversity and the stabilitytime hypothesis. In: G.M. Woodwell and H.H. Smith (eds.), Diversity and stability in ecological systems, pp. 71-81. Brookhaven Symposium No. 22, Biology Department, Brookhaven National Laboratory.

Silvertown, J., M.E. Dodd, D.J.G. Gowing and J.O. Mountford. 1999. Hydrologically defined niches reveal a basis for species richness in plant communities Nature, 400: 61-63.

Smith, B. and J.B. Wilson. - 1996. A consumer's guide to evenness indices. Oikos, 76: 70-82.

Snelgrove, P., T.H. Blackburn, P.A. Hutchings, D.M. Alongi, J.F Grassle, H. Hummel, G. King, I. Koike, P.J.D. Lambshead, N.B. Ramsing and V. Solis-Weiss. - 1997 The importance of marine sediment biodiversity in ecosystem processes. Ambio. Stockholm 26(8): 578-583

Snelgrove, P.V.R. and C.A. Butman. - 1994. Animal-sediment relationships revisited: Cause versus effect. Oceanogr. Mar. Biol. Ann. Rev., 32: 111-177.

Solbrig, O.T. (ed.). - 1991. IUBS/SCOPE/UNESCO From genes to ecosystems: A research agenda for biodiversity. IUBS

Stehli, F.G., A.L. McAlester and C.E. Helsey. - 1967. Taxonomic diversity of recent bivalves and some implications for geology. 
Geol. Soc. Amer. Bull., 78: 455-466.

Stehli, F.G., R.G. Douglas and N.D. Newell. - 1969. Generation and maintenance of gradients of taxonomic diversity. Science 164: 947-949.

Stenseth, N.C. -1984 . The tropics: cradle or museum? Oikos, 43: 417-420.

Stevens, G.C. - 1989. The latitudinal gradient in geographical range: how so many spcies coexist in the tropics. Am. Nat., 133: 240-256.

Stuart, C.T. and M. Rex. - 1994. The relationship between developmental pattern and species diversity in deep-sea prosobranch snails. In: C.M. Young and K.J. Eckelberger (ed.), Reproduction, Larval Biology, and Recruitment of the Deep-sea Benthos, pp. 118-136. New York, Columbia University Press.

Taylor, P.H. and S.D. Gaines. - 1999 Can Rapoport's rule be rescued? Modeling causes of the latitudibal gradient in species richness. Ecology, 80: 2474-2482.

Thorson G. - 1957. Treatise on Marine Ecology and Palaeoecology. In: J.W. Hedgpeth (ed.) Mem. Geol. Soc. Amer., 461-534.

Thrush, S.F., D.C. Schneider, P. Legendre, R.B. Whitlatch, P.K. Dayton, J.E. Hewitt, A.H. Hines, V.J. Cummings, S. Lawrie, J. Grant, R.D. Pridmore and S.J. Turner. - 1997a. Scaling-up from experiments to complex ecological systems: Where to next? J. Exper. Mar. Biol. Ecol., 216: 243-254.

Thrush, S.F, R.B. Whitlatch, R.D. Pridmore, J.E. Hewitt, V.J. Cum- mings and M. Maskery. - 1996b. Scale-dependent recolonization: the role of sediment stability in a dynamic sandflat habitat. Ecology, 77: 2472-2487.

Tilman, D. and J.A. Downing. - 1994. Biodiversity and stability in grasslands. Nature, 367: 363-365.

Tokeshi, M. - 1992. Dynamics of distribution in animal communities: theory and practice. Res. Popul. Ecol., 34: 249-273.

Turner, J.R.G. C.M. Gatehouse and C.A. Corey. - 1987. Does solar energy control organic diversity? Butterflies, moths and the British climate. Oikos, 48: 195-205.

Turner, J.R.G., J.J. Lennon and J.A. Lawrenson. - 1988. British bird species distributions and energy theory. Nature, 335: 539-541.

Veron, J.E.N. - 1995 Corals in Space and Time: The biogeography and evolution of the Scleractinia. University of New South Wales Press, Sydney. 321pp.

Williams, C.B. - 1964. Patterns in the Balance of Nature and Related Problems in Quantitative Ecology. Academic Press, New York.

Wright, D.H. - 1983. Species-energy theory: an extension of species-area theory. Oikos, 41: 496-506.

Zajac, R.N. - 1999. Understanding the sea floor landscape in relation to impact assessment and environmental management in coastal marine sediments. In: J.S. Gray, W Ambrose and A. Szaniawska (eds.), Sediment ecology and Biogeochemical cycling. NATO Advanced Study Workshop, 1997 Hel, Poland. Dordrecht, Kluwer. 